\section{La mirada lúcida. Desafíos en la producción y recepción de imágenes en la comunicación contemporánea}

Leandro Allochis*

\begin{abstract}
Resumen: El análisis de un discurso visual particular permite poner en discusión la complejidad de la dinámica de producción y recepción de mensajes visuales en los medios contemporáneos y los intensivos procesos de desestructuración y reestructuración a las que se encuentran sometidas las prácticas de reproducción simbólica del mundo mediante las imágenes. Así, se pone en evidencia un escenario caracterizado por una creciente generación de espectadores conocedores de los intentos por conferir un halo de novedad al texto visual, mediante mecanismos de representación sostenidos por la hipertextualidad y la hibridación de géneros y referentes. La no reposición de estas estrategias de espectáculo por otras nuevas, están comenzando a mostrar sus fisuras ante unos espectadores cada vez más formados y conocedores de las particularidades de la imagen en los medios. Un estado de situación en que la vida en iconósfera plantea nuevos desafíos tanto para receptores como para productores del discurso visual y solicita una interpelación crítica por parte de los profesionales de la comunicación, para comenzar a ensayar respuestas y proponer nuevos vínculos para con los públicos contemporáneos.
\end{abstract}

Palabras clave: imágenes - comunicación - hipertextualidad - hibridación - discurso visual - espectador.

[Resúmenes en inglés y portugués en la página 36]

(*) Profesor de Artes Visuales. Fotógrafo y artista visual. Se forma en las disciplinas de Iconografía y Simbología del Arte (Universidad de Sevilla), Historia de la Moda (Instituto Andaluz de Teatro), Sociología del Arte (UBA) y Semiótica del Arte (IUNA). Es docente del Museo Nacional de Bellas Artes de Buenos Aires, la Facultad de Diseño y Comunicación de la Universidad de Palermo y el Centro de Diplomacia Karina Vilella.

\title{
Introducción
}

"La imagen tiene significación porque hay personas que se preguntan sobre su significado, ya que una imagen de por sí no significa nada" (Vilches, 1983).

Sobre el final de la película El mago de $\mathrm{Oz}$ (Metro Goldwyn Mayer, 1939) el poderoso mago queda en evidencia cuando Toto, el perrito de Dorothy descubre su verdadera apariencia al descorrer la cortina que lo resguarda. La imagen del temible mago solo resulta 
ser un pequeño hombre que amplifica su voz mediante un artefacto tecnológico. Expuesto su mecanismo, el mago intenta mantener su poder, suplicando: "No le presten atención al hombre que está detrás de la cortina".

Figurémonos ahora que nuestro Mago de $\mathrm{Oz}$ actual es la imagen mediática, con el poder que esta ha obtenido en las últimas décadas. Este poder, identificado y nombrado por Enrico Fulchignoni en su texto "La civilización de la imagen" (Petit Bibliothéque Payot, Paris, 1975) nos hace ver que la sociedad de la imagen ha crecido en forma densa y diversificada. Así desde fines del siglo XX ha sido cada vez más frecuente calificar a la sociedad actual como "civilización de la imagen", fascinada por los medios y las tecnologías de la información y la comunicación, con un conocimiento del mundo mediado y condicionado por los mensajes masivos y por las imágenes en particular. Mirsoeff (2003) llega a postular que las imágenes han adquirido en la actualidad una importancia tal que han desplazado al texto escrito en la comunicación social contemporánea y posmoderna, convirtiéndose en el vehículo principal para la difusión de mensajes. Si la experiencia humana actual es cada vez más visual y "la vida moderna se desarrolla en la pantalla" (Mirzoeff, 2003) debemos reconocer que este fenómeno ha creado en consecuencia, un escenario donde el régimen de lo visible se ha modificado cualitativamente, cambiando el modo de producción y recepción de los mensajes. Esta imagen icónica como modalidad de comunicación pone en evidencia cada vez más su doble estatuto estético-simbólico, donde la representación mental visualizable, completa y lúcida, depende de un espectador formado y preparado. Entre estas nuevas modalidades se encuentra la puesta en discusión por parte de los receptores de la noción de naturalización de la imagen y el discurso construido por los medios como algo dado, existente y monolítico. Conscientes que la imagen y la magia del espectáculo se completan en su significado mediante la participación intelectual e interpretativa de los receptores (Vellegia, 1999), los públicos comienzan a intervenir de nuevas maneras sobre los textos mediáticos, entendiendo la percepción de las imágenes como un acto de animación, una acción simbólica donde los observadores animan a las imágenes, como si vivieran y nos hablaran (Belting, 2007).

Para evidenciar que las prácticas de producción y reproducción simbólica del mundo mediante las imágenes, se encuentran sometidas a intensivos procesos de desestructuración y reestructuración, analizaremos un discurso visual particular, que nos ayudará a comprender el mecanismo ficcional que los medios utilizan para sostener el estandarte de "nuevas imágenes", que alimentan la pasión por lo nuevo o neomanía, como rasgo distintivo de la mentalidad moderna (Erner, 2010). Este análisis permitirá desmontar el andamiaje estético y simbólico de un corpus visual en relación a los medios masivos y las representaciones simbólicas del poder y los valores asociados a la masculinidad hegemónica y patriarcal. Específicamente se compararán dos imágenes de diferentes épocas, contextos y funciones: una foto promocional de un cantante de hip hop (2003) y una pintura que retrata al Rey de Inglaterra Enrique VIII (1537). Desde el estudio comparativo intentaremos explicitar los mecanismos formales y simbólicos de los que se valen las representaciones actuales y reconocer sus citas y apropiaciones del pasado como operatorias de reciclaje y así poner en discusión la complejidad de la dinámica de producción y lectura de mensajes visuales en un escenario de comunicación masiva caracterizado desde los receptores con una creciente generación de espectadores concientes del estatuto ficcional de la imagen mediática; 
actitud que pondrían en riesgo un contrato de lectura que hasta hace poco tiempo parecía monolítico con unos productores visuales caracterizados por una actitud de confianza excesiva en la credibilidad del público ante los mecanismos de simulación de los textos visuales. Productores cobijados bajo el paradigma posmoderno de espectadores pasivos y consumidores hipnóticos de mensajes, como bloques compactos y unilaterales de sentido, observadores de teatralidades por verdades.

\section{Las particularidades del discurso visual en la comunicación masiva}

Para ubicarnos en el espacio temático, repasaremos algunas proposiciones fundamentales sobre el funcionamiento de la imagen en la comunicación actual y en relación a la dinámica relacional entre productores y receptores. Partiremos del concepto sobre la relación solidaria y necesaria que existe entre la imagen y su receptor, como sujeto que completa y determina su lectura, ya que el texto visual mediante el cual se llevan a cabo las estrategias de comunicación, funciona como una máquina semántico-pragmática que pide ser actualizada en un proceso interpretativo por parte del lector (Eco, 1979). Para Eco los signos icónicos poseen un carácter convencional, que estaría probado por la historia del arte donde los artistas crearon reglas de traducción de los signos icónicos para poder expresar los contenidos de la realidad. Entonces no sería el objeto de la imagen lo que motiva la organización de la expresión, sino el contenido cultural que le corresponde a ese objeto. Vilches (1983) acompaña esta postura cuando determina que representar icónicamente es transcribir según convenciones gráficas y propiedades culturales/convencionales del objeto, por lo que la imagen es comprensible por medio de reglas culturales ya adquiridas y será el observador quien determine que zonas de semejanza del objeto icónico puede actualizar. Es entonces mediante los aportes de la pragmática y la semiótica textual que podremos interrogar sobre el funcionamiento de estos textos, donde el significado de una imagen se manifiesta a través de una expresión icónica, determinado por las formas culturales y convencionales de la percepción de la realidad, así como por las técnicas que dominan las relaciones de producción cultural, mediante imágenes-textos-culturales que contienen un mundo real o posible y obedecen a estructuras comunicativas intertextuales.

\section{De la imagen a los imaginarios sociales}

Durante el Siglo XX la civilización humana ha experimentado, formulado e impulsado como en ningún otro tiempo de su historia, el desarrollo de los medios de comunicación a escala masiva. Luego de la Segunda Guerra Mundial, la radio, la televisión, el cine y los medios impresos se convirtieron en vehículos asequibles para todo público, conformando el fenómeno de la comunicación masiva. Esta cultura de masas se ha venido identificando como una de las matrices más poderosas que reproduce y en ocasiones renueva representaciones y esquemas simbólicos del mundo (Aguiar, 1997). Identifiquemos ahora los efectos del discurso visual en su dimensión pragmática y los alcances de la imagen a la hora de conformar significados a nivel individual y colectivo, ya que el concepto de imagen 
solo puede enriquecerse si se habla de imagen y medio como dos caras de una moneda. Si las imágenes que fundamentan significados, tanto artefacto que ocupa su lugar en cada espacio social, llegan al mundo como imágenes mediales, entonces los medios de la imagen también tendrán una participación en las atribuciones de sentido de dicha la imagen (Belting, 2007). Así la imagen en su circulación masiva se conforma como un instrumento dinámico para la conformación y legitimación de imaginarios sociales; imaginarios que Koss define como matrices de sentido existencial, elementos indispensables en la elaboración de sentidos subjetivos atribuidos al discurso, representaciones globales o ideas-imágenes. Este imaginario social no es la representación de ningún objeto o sujeto, sino una incesante creación socio-histórica de figuras, formas e imágenes que proveen contenidos significativos y los entretejen en las estructuras simbólicas de la sociedad (Ponciano, 2006).

Siguiendo a Vilches (1983) nos preguntarnos ahora como se construyen estas proposiciones sobre el mundo a partir de los discursos visuales; que modelos instituyen y como logran ser recepcionadas y aceptadas como modelos-reflejos del mundo. Para acotar la pregunta a nuestro objeto de análisis, plantearemos como los medios construyen imágenes que apelan a comunicar el concepto de masculinidad en circuitos publicitarios y promocionales. Al revisar las representaciones de género que la publicidad y el cine han difundido durante el Siglo XX y especialmente luego de la II Guerra Mundial, vemos que se han sostenido bajo ciertas modelizaciones y repertorios de estereotipos de una masculinidad de tipo hegemónica, caracterizada por rasgos de fuerza, autoridad y riqueza. Esta construcción social de lo masculino ligada a la noción de importancia y poder como principales mandatos y atributos culturales del varón (Abarca Paniagua, 1999), serán ampliamente difundidas en el cine de los años 50 con películas como The Wild One (1953) y A Streetcar named desire (1951), donde Marlon Brando encarnará tales estatutos, delineados previamente por John Wayne en el genero Wstern. El prototipo hegemónico de masculinidad, representado por la supremacía física y la virilidad explicitado mediante recursos como la ostentación de un cuerpo muscular, de espaldas anchas, gruesos brazos y abdomen tallado (Aguiar, 1997), son utilizados por la industria cultural para promover en el consumidor la fantasía de acceso a tal modelización, mediante la identificación y el consumo del producto.

Si bien en las últimas décadas han surgido nuevas posturas con respecto a estas definiciones, como la planteada por Judith Butler quién propone pensar el género como una construcción discursiva y acto intencional y performativo en tanto construcción teatral, continuamos viendo en las imágenes mediáticas una persistencia de representación de la identidad masculina sujeta a modelizaciones herméticas. En esta dificultad de los medios para definir el genero por fuera de las representaciones arquetípicas las masculinidades emergentes son absorbidas por la imagen y reducidas a estereotipos de representación, mas que ideologías. Un claro ejemplo es la serie de cortos publicitarios para los refrescos japoneses Suntory (2009) que confrontan a dos tipos de "machos" diferenciados: los Hoso Macho (Macho con Estilo) aparecen como jóvenes de piel clara, gestos delicados y cuerpos estilizados y delgados vestidos con ropa brillante y ajustada, mientras que los Gori Macho (los Macho Gorilas) son representados como hombres que exhiben sus cuerpos macizos y bronceados vestidos solamente con un slip deportivo y su rostro oculto bajo máscaras de lucha libre. 
Estas performances de género se ponen en evidencia mediante una dimensión estética, particularmente apoyada en el cuerpo y un catálogo indumentario, teniendo en cuenta que la moda es una de las expresiones más representativas del moldeamiento social. Esta relación solidaria de la indumentaria a la hora de construir un texto ideológico-visual sobre el cuerpo se da gracias a las cualidades comunicativas y expresivas de las que goza el vestido, donde el objeto-indumentaria pierde su funcionalidad física para adquirir valor comunicativo, convirtiéndose ante todo en signo y en segunda instancia, en objeto (Eco, 1972). Según Gonzáles (2010) desde la sociedad industrial se configuró a los consumidores para buscar prendas no por su valor de uso, sino por su valor simbólico. Así el carácter simbólico del vestido coexiste junto a su carácter comunicativo, entendiendo a la indumentaria como un lenguaje articulado, sustentado por códigos y convenciones, muchos de ellos continuos y estables en el tiempo. En el caso de la construcción de imágenes que modelizan prototipos de géneros hegemónicos, la indumentaria resulta especialmente funcional como mecanismo de normativización y jerarquización del cuerpo. Además de reconocer este nivel simbólico de la indumentaria, que Bordieu identifica cuando la prenda de vestir se traduce en capital social y cultural (Erner, 2010), debemos recordar que la moda, al igual que la imagen, es un signo, una representación que existe en tanto es referenciada a otra cosa en ausencia, por parte del receptor.

\section{La actualización como estrategia y mecanismo de la producción visual}

Para analizar nuestro caso particular, retomaremos la premisa de que toda imagen icónica es un artefacto social que transmite significado (una apariencia que siempre remite a «algo más») y se estructura por convenciones, lo que Eco designa como "sentido contextual" y Canclini (1992) define como la "heterogeneidad multitemporal" propia de la cultura visual y los textos sociales contemporáneos. Para interpretar y completar el texto visual en este nivel intertextual, surge nuevamente la importancia de la competencia del destinatario, formada por las referencias estilísticas e históricas que son actualizadas mediante transcripciones no siempre evidentes para los consumidores (Vilches, 1983). Teniendo en cuenta que analizaremos retratos de personas, nos detendremos a delinear ciertos conceptos sobre la constelación persona-cuerpo-imagen. Cada vez que aparecen personas en una imagen, se están representando cuerpos que portan un sentido metafórico, ya que se muestran cuerpos pero significan personas. En estas imágenes de cuerpos el ser humano se encarna para llevar a cabo su juego de roles, entendiendo el cuerpo entonces en un sentido cultural (Belting, 2007). Siguiendo a Belting, las dos imágenes elegidas para el análisis se contemplarán entonces desde la perspectiva ideológica del cuerpo y su particular estatuto en el siglo XX, donde se pretende re-crear el cuerpo mediante imágenes que cumplan ciertos ideales prescriptivos, en nuestro caso el de "masculinidad".

El corpus esta conformado por una serie de fotografías del cantante de hip hop estadounidense 50 Cent, para la promoción de su álbum Get Rich Or Die Tryin' (2003) y una de las pinturas monárquicas más paradigmáticas de la historia del arte, como es el retrato de Enrique VIII, atribuido a Hans Holbein el Jóven. Un acercamiento desde el análisis sintáctico/semántico/pragmático de las iconografías, marcas indumentarias y atributos físicos 
de estos retratos, nos permitirá indagar sobre qué expresa la imagen acerca del cuerpo que documenta y que concepción del cuerpo se construye en estas imágenes (Belting, 2007) en relación a los imaginarios sociales a los que remiten, mediante sus huellas hipertextuales asociadas a representaciones tradicionales de masculinidad hegemónica.

\section{La performance de opulencia en la cultura hip hop}

La cultura del rap y el hip hop, surgida de las comunidades afroamericanas y latinoamericanas de los barrios populares neoyorquinos de Bronx, Queens y Brooklyn, construye desde principios de la década de 1980 un estilo particular de indumentaria masculina, con un evidente interés por la demostración de poder y opulencia, mediante el uso de joyería y prendas maximizadas. La ostentación presente en la superficie de los materiales y la escala de las prendas y la joyería, impulsada quizás por el afán de demostrar el éxito por sobre los orígenes marginales, funcionan como símbolos de éxito económico y fortaleza física. Las referencias hipertextuales de este catálogo de indumentaria y accesorios de poder se pone especialmente en evidencia en la estética del cantante de hip hop 50 Cent, presentes en sus fotos y presentaciones durante la promoción de su álbum Get Rich Or Die Tryin' (2003). Estas fotografías construyen una imagen del cantante mediante un cuerpo, un vestuario y un repertorio gestual (pose), que desde el imaginario popular y la tradición del retrato son asociadas a modelos hegemónicos de masculinidad.

Entre estas huellas de sentido podemos citar la práctica del sagging, consistente en la exhibición de la banda elástica y zonas de la ropa interior como exterior (Blackman, 2009) que si bien podría ser consecuencia del uso de ropa ancha y pantalones caídos (jeans baggy) surgido en las cárceles donde no existían variedad de talles y se prohibía el uso de cintos (Christian, 2007), su aparición en las fotografías que Herb Ritts realizara para Calvin Klein Underwear (1991), con el cantante Marky Mark (luego devenido en actor como Mark Wahlberg) consolidarían la asociación de esta modalidad con la masculinidad viril. Otro elemento que encontramos en estas imágenes son los llamativos accesorios de pesada joyería (denominada con el término bling bling, que habría surgido de la onomatopeya jamaiquina del sonido de las joyas y los destellos que producen), como símbolo del enriquecimiento, fama y riqueza. Esta tendencia sería popularizada por los seguidores del subgénero gangsta rap, que inspira su vestimenta en la iconografía gángster mediante el uso de pieles, trajes de llamativos colores y texturas, camisas de seda y zapatos de cocodrilo (Wilkinson, 2011).

Nos detendremos ahora en el uso por parte de 50 Cent de prendas y accesorios militares y policiales como pistoleras y chalecos tácticos antibalas (proof vest). Esta referencia a la pechera/armadura se convertirá en un objeto de identidad y elemento fetiche del cantante, hasta convertirlo en 2005 en packaging de su DVD Bulletproof US para PlayStation 2, al envolver la caja del disco con un mini chaleco táctico. La actualización del artefacto-armadura que modela y maximiza el tórax masculino se extenderá a otros músicos del género como Usher, quien viste chalecos tácticos y petos militares inspirados en el Imperio Romano, en sus presentaciones para la NBA AllStar en Arlington (Febrero del 2010) y Nashville (Diciembre del 2010). Por otro lado, el cantante de hip-hop estadounidense, Pharrell Williams 
diseña para la Colección de Otoño 2010 de la firma italiana Moncler, un chaleco masculino acolchado, con cerraduras laterales de velcro, recreando el bullet-proof vest militar.

Esta particular configuración de cuerpo maximizado y jerarquizado que 50 Cent produce, se instala dentro del paradigma del Siglo XX que afectó al cuerpo natural haciéndolo parecer insuficiente y permitiendo que las tecnologías lo sustituyeran con prótesis corporales. Una metamorfosis avalada por los medios y la publicidad que difunden un mandato de semejanza con modelos corporales, exhibidos mediante imágenes-cuerpo en los medios. Una escenificación de un cuerpo cuya referencia resulta en gran medida incierta, por lo que el cuerpo en imagen se convierte en invención cultural: "Vivimos como los cuerpos pantomímicos que somos y no con los cuerpos anatómicos que poseemos” (Belting, 2007).

\section{Las modelización del cuerpo masculino en Enrique VIII}

Pondremos ahora en diálogo a las fotografías de 50 Cent con uno de los retratos más conocidas de Enrique VIII (1491-1547), para establecer ciertos vínculos en relación a la representación del cuerpo masculino, atendiendo tal comparación bajo las particulares intenciones de significado ligadas al tiempo (Belting, 2007).

Se trata de una pintura mural (Palacio de Whitehall, Londres) del Rey de Inglaterra, realizada por Hans Holbein El Joven en 1537 y sus posteriores copias tras la destrucción por el fuego del original en 1698. En este retrato de cuerpo entero, se representa al monarca de pie en una pose heroica, con las piernas abiertas y sus pies plantados separadamente. Esta frontalidad, el distanciamiento y el hieratismo de la pose son sintomáticos del poder y la personalidad del rey. En el retrato heredado de Holbein, Enrique VIII viste con riqueza: tramas de damasco, bordados, piel, calzas ajustadas, medias, calzado en pico de pato, justillo sin mangas (chaqueta) y jubón (que luego evolucionará en chaleco).

El monarca porta numerosas piezas de joyería, que en tamaño, calidad y cantidad resultan funcionales a la definición del status social. Se observan piezas de orfebrería incrustadas en el jubón, anillos, medallón y collar de eslabones de oro sobre el pecho, de uso común entre los oficiales del Estado o de la casa real, usualmente con iniciales, insignias de rastrillos y rosas de los Tudor.

Para remarcar la ingle y proyectar una imagen de masculinidad viril lleva en la entrepierna una bragueta, consistente en un triángulo protector de tejido relleno. Para remarcar los hombros el justillo posee hombreras creadas con un rollo de tejido o alas sobre los hombros. El jubón que viste el monarca, también esta acolchado con rellenos y refuerzos para generar un volumen adicional, ya que el torso abombado junto a la cintura reducida con un cinto, se consideraba signo de virilidad (Cosgrave, 2000). Esta prenda adaptada para su uso social provenía del mundo militar, remitiendo a las pecheras y armaduras militares, utilizadas sin interrupción desde el Imperio Romano y la Edad Media en forma de cota de malla y armadura de cuero o metal.

Este aspecto recargado y el acento de ciertas zonas del cuerpo mediante prendas maximizadas y rellenos será un mecanismo común en la moda masculina de las clases altas de la época. Este retrato y su conjunto de indumentaria modeladora, responde a las particularidades que asumió la imagen del cuerpo desde el Renacimiento, donde se requirió 
de una nueva escenificación del hombre, desarrollando una ficción del cuerpo y llevando sus proporciones a un esquema ideal mediante una arquitectura corporal, poniendo en conflicto la anatomía con la estética. La imagen imita y modula un cuerpo y a la vez a la dignidad del rango que dicho cuerpo busca; es decir que el cuerpo representado es cultura y no naturaleza (Belting, 2007).

\section{La actualización como estrategia}

Comparando ambos casos cabe preguntarnos que niveles de sentido se ponen en funcionamiento en la imagen del cantante y sus referencias al retrato del Siglo XVI.

Puntualicemos primero los elementos iconográficos presentes en ambas representaciones:

- Uso de indumentaria maximizada y/o muy estrecha para la ostentación de musculatura y fuerza física.

- Uso de indumentaria con relleno para aumentar la amplitud del tórax.

- Visibilidad de la ropa interior como reflejo de virilidad.

- Uso de joyas de gran tamaño, incluyendo medallones con símbolos e iniciales representativas del portador.

- Uso de armas y pieles.

- Postura erguida con piernas separadas y manos en la cintura

Estos elementos funcionan como atributos de valores convencionalmente asociados a ellos que podríamos agrupar en dos grandes ejes:

Poder: estatus social, jerarquía, pertenencia a un grupo selecto y superior.

Género: virilidad, fuerza física y cuerpo muscular.

Tales analogías estéticas y simbólicas nos permiten deducir que la estética del hip hop, particularmente en su género gangsta, cita códigos indumentarios y posturas propias de retratos cortesanos, como referencia al prestigio y poder económico y físico propio de este genero. Tal estrategia de actualización adquiere una especial connotación en el contexto de la sociedad moderna y su el abandono de las leyes suntuarias (que limitaban la posesión y el uso de ropas, pieles, joyas y ciertos colores a las clases acomodadas como símbolos de poder) para traducir una ideología de la igualdad y la libertad (Croci, Vitale, 2011). Por lo que el uso de tal repertorio indumentario en la estética hip hop mantendrá ciertas analogías sintácticas con los retratos cortesanos, pero en el contexto actual tal exhibición quedará relegada al mundo del espectáculo y la teatralización. Este carácter circular y combinatorio de los iconos fundantes será evidente solo para un observador capaz de identificar los mecanismos de representación del revival e incorporarlo como conflicto y práctica contemporánea en la producción de imágenes mediáticas.

Tal dinámica hipertextual nos lleva a pensar que no hay nuevos modelos para representar en imágenes, sino reinterpretaciones y combinatorias de prototipos del pasado. Baudrillard (1980) dice que la modernidad hace convivir lo neo y lo retro, lo moderno y lo anacrónico, en forma de ruptura que velozmente se vuelve amalgama y reciclaje. La moder- 
nidad no sería entonces la transmutación de todos los valores, sino solo su combinatoria y ambigüedad, en prácticas como las de la moda, cuando enuncia en simultáneo el mito del cambio y las estructuras y modelizaciones tradicionales. O como en referencia a la Revolución Francesa y su pretensión de ser una Roma retornada mediante citas políticas y estéticas, Benjamín (1971) postula que "La moda es un salto del tigre al pasado", cuando una "nueva" colección siempre cita un vestido de otro tiempo. Fuera de esta lógica de la hipertextualidad, donde no hay estilo de época que no tematice y recupere fragmentos del pasado de una cultura (Steimberg, 2001), y mas allá que las imágenes analizadas parezcan análogas a nivel estético, debemos puntualizar que el sentido retórico cambiará junto a la función del texto; o en palabras de Benjamín “...no se debe confundir el orden ritual donde la ostentación de los signos nunca tiene ese efecto "estético" con la moda como espectáculo, que goza estéticamente de ella misma”.

\section{Nuevos espectadores ¿Nuevos productores?}

Entonces diremos que si la imagen de 50 Cent comunica masculinidad y poder mediante vínculos hipertextuales, la recepción de textos visuales actuales requerirá de una estrategia comunicativa-visual de actualización y reinterpretación de prototipos convencionales para su completa interpretación. Esta actitud indagatoria sobre los productos culturales, nos permite comprender como los textos visuales obedecen a reglas y estrategias precisas durante su elaboración, como organización de la futura recepción por parte del espectador. No accederíamos a tales niveles de sentido sin una competencia lectora que incluya una mirada selectiva y cognoscitiva junto a la portación y uso de una enciclopedia de referencias a la hora de actualizar el texto. En la década del 80, Vilches remarcaba esta necesidad de espectadores como partícipes activos de los contratos de lectura de las imágenes mediales:

Resulta fundamental la tarea pragmática del lector al confrontar la información del texto con las de su propio saber, recorriendo el texto como un mapa y descubriendo tópicos conocidos. Las competencias del observador incluyen un sujeto cognoscitivo y un hacer interpretativo. Mediante su enciclopedia semántica, entendida como dispositivo mnemónico, el destinatario identifica el tipo de tópico que conferirá a las proposiciones de la imagen. Este tópico es reconocido por el destinatario cuando reconoce algo que "ya se sabe o ya se ha visto". Ya que el tópico es una operación que, aunque inscripta en la imagen necesita de la actualización del lector, los saberes del receptor son esenciales para establecer que tipo de pregunta dirigirá al texto para actualizarlo. Dado que el tópico es una operación mayormente pragmática podríamos decir que el lector o destinatario es el principal elemento de la significación visual (Vilches, 1983).

Tres décadas después y con la ayuda de Internet pareciera surgir una nueva generación de receptores, que cumplirían con los requerimientos expuestos por Vilches, creando una 
actualidad comunicativa con nuevos vínculos entre los productores y receptores de discursos visuales. Estos receptores que han dejado de confiar en las imágenes como referencia de lo real, crean lo que Michael Focault designó como "crisis de la representación" (Belting, 2007). La disponibilidad de información del público mediante Internet, como fuente de saberes de libre acceso y diccionario completo de referencias, permite fácilmente poner en evidencia los montajes y mecanismos de reciclado con los que se construyen los textos visuales contemporáneos. Entonces si este mecanismo de la reinvención de antiguas imágenes y estereotipos, mediante la hibridación de géneros y referentes para intentar conferir un halo de novedad, pareciera estarse quedando sin repertorios de combinatorias, cabe preguntarnos si los productores visuales están preparados para una revolución de los espectadores lúcidos. La revolución de los públicos como riesgo latente no es una idea nueva. Ya en 1930 Federico García Lorca visionaba en forma de texto dramático ( $E l$ público y El sueño de la vida), una escena de tenor casi apocalíptico donde el público de un teatro abandona sus butacas sumisas, tomando el escenario por asalto y arremetiendo contra actores y decorados, poniendo en evidencia las simulaciones del género y aboliendo su estatus de receptores pasivos. El síntoma es retomado en el film estadounidense The Truman Show (1998) dirigida por Meter Weir y protagonizada por Jim Carrey y Ed Harris. En este caso el público esta representado en un solo hombre, que tras asumir durante toda su vida el mundo que le rodea como real, descubre el carácter de simulacro de su entorno vital y se rebela reclamando una vida real, fuera del estudio de televisión. El film además de remitir a la reflexión contemporánea sobre la sociedad del espectáculo de Guy Debord y la cultura del simulacro planteada por Jean Baudrillard, muestra en su escena final como Truman, este espectador nacido y criado en un mundo de representaciones, traspasa la puerta de salida de aquel mundo construido, ubicada en el horizonte; limite físico y a la vez metafórico de su ciudad (Torregrosa, 2010).

Posiblemente haya sido desde el mundo del arte, donde se comenzó a discutir la precariedad de la representación como reflejo de la realidad, con obras conceptuales como Beauty Composites (1982) donde la artista americana Nancy Burson fusiona fisonomías de hombres y mujeres de diferentes orígenes y épocas, creando retratos de personas inexistentes, o la serie Fauna (1987) del artista catalán Joan Fontcuberta, con fotografías que cumplen con los estatutos estéticos de las imágenes científicas a la vez que muestran animales ficticios. Desde los ámbitos mediáticos será el cine quién visualice este panorama a tiempo, capitalizando el conocimiento del público sobre lo performático del soporte y accediendo a un nuevo contrato de lectura al develar el mecanismo en forma de backstage, convirtiéndose incluso este material novedoso en un bonus para la película. En cambio la imagen fija, especialmente la fotografía publicitaria y editorial, ha comenzar a admitir sus camuflajes solo ante la aparición de presiones éticas y sociales, con acciones como la inclusión en las fotografías de la frase: "Fotografía retocada para modificar la apariencia física de la persona”. Esta condición por ahora incorporada en minoría, esta cobrando cada vez mas fuerza con las propuestas de los de ley de los gobiernos de Francia y el Reino Unido para regular el uso de Photoshop y el retoque de fotografías destinadas a revistas y publicidad. La diputada francesa Valérie Boyer, del partido UMP y otros 50 parlamentarios crearon una ley para luchar contra lo que ellos consideran una imagen deformada de los cuerpos de las mujeres en los medios de comunicación. "Estas imágenes pueden hacer 
creer en una realidad que a menudo no existe", comentó Boyer, añadiendo que la ley debe aplicarse a las fotografías de prensa, a las campañas políticas, a la fotografía artística y a las imágenes de los envases (Ética y publicidad, 2011). Resulta significativo que estén siendo los mismos protagonistas de las fotografías quienes reclaman por los límites éticos de la manipulación de la imagen, particularmente las alteraciones en la apariencia de los modelos en relación a sus rasgos de filiación étnica o social, como el aclaramiento de piel, como en los casos de la cantante Beyoncé Knowles, en su gráfica para la firma cosmética L’Oreal en 2008 (Fouilloux, 2012); el de la actriz Gabourey Sidibela, protagonista de la película Precious en su portada de la revista Elle, en 2010 (La Razón, 2010) o el de la actriz hindú Aishwarya Rai Bachchan, también en la revista Elle de India, en 2010 ( La Gaceta , 2010). Si la no reposición de estas estrategias de espectáculo por otras nuevas están comenzando a mostrar sus fisuras ante espectadores cada vez más formados y conocedores de las particularidades ortopédicas de la imagen en los medios, cabe preguntarnos si los productores visuales estamos preparados para ofrecer nuevas modalidades de construcción y lectura, para cuando el público decida inhabilitar el contrato de lectura sostenido en la indiferencia a la ficcionalidad?

\section{Conclusión}

Como afirma Prieto, nuestra actualidad profusamente visual ha generado un modo contemporáneo de mirar, conocer y pensar, enmarcado en un multiculturalismo típico de la posmodernidad. Si bien en el juego comunicativo, el texto visual es algo definitivo que viene dado como producto acabado, son las múltiples versiones que los usuarios pueden leer en ellas las que completan su sentido, como ya visionaba Marcel Duchamp al postular "quien mira es quien hace el cuadro".

Si desde fines del siglo XX es frecuente calificar a la sociedad actual como "civilización de la imagen", por el conocimiento del mundo mediado y condicionado por las imágenes, ha surgido en consecuencia una nueva generación de consumidores de imágenes con una base cultural y una alfabetización digital, conformada por destrezas mentales, hábitos operacionales y talante interactivo (Martín-Barbero, 2010). Si bien no se educa visualmente de manera sistemática como se hace con la lengua o la escritura, el acceso a Internet está permitiendo a los lectores comenzar a ejecutarle nuevas preguntas al texto visual. Esta educación visual forma espectadores activos y les permite un consumo coherente de imágenes codificar y decodificar mensajes visuales accediendo a sus dimensiones estéticas, sociales y políticas. Sin tal actitud Eco puntualiza que se dejaría de interrogar a la imagen, para ser secuestrada por la norma y el estereotipo: "La civilización democrática solo se salvará si se hace del lenguaje de la imagen una provocación a la reflexión crítica y no una invitación a la hipnosis" (Eco, 1965).

Pareciera entonces estarse gestando una nueva generación de espectadores cada vez mas formados, conscientes del poder de la industria cultural en la conformación de imaginarios colectivos y sus mecanismos en la producción de discursos, como el reciclaje y actualización cíclica de prototipos en forma de novedad. Si bien este nuevo público conocedor del estatuto ficcional de la imagen mediática, permite pensar una relación más 
democrática con las imágenes de consumo, también estaría poniendo en crisis un contrato de lectura construido sobre la base de credibilidad masiva, poco difícil de conseguir hoy en día. Aunque el escenario comunicacional actual pareciera seguir funcionando bajo tales paradigmas de credibilidad acordada, es innegable que la vida en iconósfera plantea nuevos desafíos tanto para receptores como para productores del discurso visual, por lo que resulta urgente una interpelación crítica por parte de los profesionales de la comunicación, para comenzar a ensayar respuestas y proponer nuevos vínculos para con los públicos. Si los comunicadores de imágenes han sustituido creatividad por re-creación, naturalizando las estrategias de mimesis y reciclaje por novedad, resulta urgente pensar nuevas proposiciones sobre las cuales construir el texto mediático; quizás desde un acuerdo más horizontal y transparente entre productores y espectadores.

Para plantearlo en términos del Mago de $\mathrm{Oz}$, ya "sabemos" que Dorothy "sabe" que hay detrás de la cortina. Por ahora Dorothy no ha tirado abajo los telones; espera distraída, pero no ignorante, la aparición de nuevas novedades; novedades más reales, surgidas de la creatividad y no de la simulación.

\section{Referencias Bibliográficas}

Abarca Paniagua, H. (1999). Discontinuidades en el modelo hegemónico de masculinidad en Feminidades y Masculinidades. Estudio sobre salud reproductiva y sexualidad en Argentina, Chile y Colombia. Comp. por Mónica Gogna. Buenos Aires: CEDES.

Aguiar, J. (1997). ¡Ámame por ser bello! Masculinidad=cuerpo+eros+consumo en Revista La Ventana, no 5. México: Universidad de Guadalajara.

Alberdi, M. (2004). "La imagen digital. ¿Nuevos interrogantes para la semiótica" en La Trama de la Comunicación, Vol. 9, Anuario del Departamento de Ciencias de la Comunicación. Facultad de Ciencia Política y Relaciones Internacionales, Universidad Nacional de Rosario. Rosario. Argentina. UNR Editora.

Baudrillard, J. (1980). El intercambio simbólico y la muerte . Caracas: Monte Ávila.

Benjamin, W. (1971). Angelus Novus. Barcelona: Edhasa.

Belting, H. (2007). Antropología de la imagen. Buenos Aires: Katz Editores.

Blackman, C. (2009). 100 años de moda masculina. Barcelona: Blume.

Colombres, A. (1987). Sobre la cultura y el arte popular . Buenos Aires: Ediciones Del Sol.

Cosgrave, B. (2000). Historia de la Moda. Desde Egipto hasta nuestros días. Barcelona: Gustavo Gili.

Christian, M. (2007). The facts behind the saggin' pants craze en Jet Magazine, Vol. 111,N. ${ }^{\circ}$ 18. Chicago: Johnson Publishing Co.

Croci P., Vitale A. (2011). Prólogo en Los cuerpos dóciles. Hacia un tratado sobre la moda. Buenos Aires: La Marca Editora.

Darley, A. (2002). Cultura Visual Digital. Espectáculo y nuevos géneros en los medios de comunicación. Barcelona: Paidós.

de Morales, D. (2010). Cultura tecnológica, innovación y mercantilización en Convergencia digital y diversidad cultural en Mutaciones de lo visible . de Morales, D. Dênis (Comp.). Buenos Aires: Paidós. 
Eco, U. (1968). Apocalípticos e Integrados. Barcelona: Lumen.

Eco, U. (1972). El hábito hace al monje en Psicología del Vestir. Barcelona: Editorial Lumen. Ética y publicidad (2011). El retoque digital en publicidad. Recuperado el 05/06/12 de http:// artlop.wordpress.com/2011/08/27/el-retoque-digital-en-publicidad/

Erner, G. (2010). Sociología de las tendencias. Barcelona: Gustavo Gili.

Espada Calpe, J. (2004). Poder, masculinidad y virilidad en ponencia Curso Técnico Especialista en Igualdad de Oportunidades en el Empleo, IMUMEL, 7 de Mayo de 2004. Albacete, España.

Fouilloux, P. (2012). Polémica por “blanqueamiento" de Beyoncé. Recuperado el 01/02/12 de http://www.biut.cl/content/actualidad/2012/01/1-2347-9-polemica-por-blanqueamientode-beyonce.shtml

García Canclini, N. (1992). Culturas híbridas. Estrategias para entrar y salir de la modernidad. Buenos Aires: Sudamérica.

García Canclini, N. (1999). Narrativas sobre fronteras móviles entre estados Unidos y América Latina, en Bayardo, R. y Lacarrieum. (Comp.) La dinámica global/local. Buenos Aires: Ediciones CICCUS.

González, L. (2010). Roland Barthes se mete con la moda en Reflexión Académica en Diseño y Comunicación NoXIII. Año XI, Vol. 13. Buenos Aires: Universidad de Palermo.

García Lorca, F. (1978). El público. Barcelona: Ed. Seix Barral.

La Gaceta (2010). El retoque digital a una modelo en una revista volvió a causar polémica. Recuperado el 15/02/12 de http://www.lagaceta.com.ar/nota/414893/Espect\%C3\%A1culos/ retoque-digital-modelo-revista-volvio-causar-polemica.html

La Razón.es (2010). ELLE aclara la piel de Gabourey Sidibe: la polémica está servida. Recuperado el 04/01/12 de http://www.larazon.es/noticia/3914-elle-aclara-la-piel-de-gaboureysidibe-la-polemica-esta-servida

Martín-Barbero, J. (1999). Globalización comunicacional y descentramiento cultural en Bayardo, R. y Lacarrieum. (Comp.) La dinámica global/local. Buenos Aires: Ediciones CICCUS.

Martín-Barbero, J. (2010). Convergencia digital y diversidad cultural en Mutaciones de lo visible. de Morales, D. Dênis (Comp.). Buenos Aires: Paidós.

Mirzoeff, N. (2003). Una introducción a la cultura visual. Barcelona, Paidos.

Ponciano, K. (2006). Los imaginarios sociales como espacio analítico para la sociología centroamericana. En Conferencia del X Congreso Centroamericano y I Congreso Nacional de Sociología. Antigua Guatemala Prieto, P. (2009) Cultura visual de masas. Recuperado el 01/06/12 de http://www.darfruto.com/6_cultura_visual.htm

Steimberg, O. (2001). "Moda y estilo a partir de una frase de Walter Benjamín" en deSignis, No 1: La moda, representaciones e identidad, Barcelona - Buenos Aires: Federación Latinoamericana de Semiótica - Gedisa.

Torregrosa, M. (2010). El show de Truman. Estrategias metaficcionales y quiebras del simulacro en Revista Área abierta, no 25, Marzo 2010. Universidad Complutense de Madrid.

Vellegia, S. (1999). Imágenes e imaginarios en la tensión global/local en La dinámica global/ local . Bayardo, R. y Lacarrieum. (Comp.). Buenos Aires: Ediciones CICCUS.

Verón, E. (1988). Prensa escrita y teoría de los discursos sociales: producción, recepción, regulación. París: Langage, discours et societés, $\mathrm{N}^{\circ} 4$.

Vilches, L. (1983). La lectura de la imagen. Barcelona: Paidos Comunicación. 
Wilkinson, K. (2011). Vestirse en el hip hop . Recuperado el 05/06/12 de http://www.bershka. me/es/vestirse-en-el-hip-hop-NDY5NTY.html

Summary: The analysis of a particular visual discourse allows the discussion about the complexity of the dynamics of production and reception of visual messages in contemporary media and the intensive processes of structuring and restructuring the world symbolic reproduction practices into images. In this context, we face an scenario characterized by a growing generation of viewers awared of the attempts to confer an aura of novelty to visual text representation mechanisms supported by the hypertext and hybridization of genres and referents. The not replacement of these strategies into new ones, are beginning to show their cracks in front of increasingly trained individuals who are more conscious about the particularities of images on the media; a situation where an iconosphere life poses new challenges for both recipients and producers of visual discourse and request a critic interpellation by communication professionals to propose new answers and new links with contemporary audiences.

Key words: images - communication - hypertext - hybridization - spectator - visual speech.

Resumo: A análise de um discurso visual particular permite pôr em discussão a complexidade da dinâmica de produção e recepção de mensagens visuais nos meios contemporâneos e os intensivos processos de desestruturação e reestruturação às que se encontram submetidas as práticas de reprodução simbólica do mundo mediante as imagens. Assim, se evidencia um cenário caracterizado por uma crescente geração de espectadores conhecedores dos intentos por conferir um halo de novidade ao texto visual, mediante mecanismos de representação sustida pela hipertextualidade e a hibridação de gêneros e referentes. As não reposições destas estratégias de espetáculo por outras novas, estão começando a mostrar suas fissuras ante uns espectadores cada vez mais formados e conhecedores das particularidades da imagem nos meios. Um estado de situação no qual a vida em iconosfera apresenta novos desafios tanto para receptores como para produtores do discurso visual e solicita uma interpelação crítica por parte dos profissionais da comunicação, para começar a ensaiar respostas e propor novos vínculos para com os públicos contemporâneos.

Palavras chave: imagens - comunicação - hipertextualidade - hibridação - discurso visual - espectador. 